\title{
Public Employees' Motivation: A Case of the Municipality of Elbasan, Albania
}

\author{
Matilda Lopari ${ }^{1}$ \\ Vilma Pepa ${ }^{2}$
}

1 University of New York, Tirana, Department of Business Administration, matildalopari@unyt.edu.al

2 University Aleksandër Xhuvani, Elbasan, vilmapepa@gmail.com

\section{Doi:10.5901/ajis.2015.v4n3s1p565}

\section{Abstract}

\begin{abstract}
Employees, whether working in private organizations or public institutions, need to be motivated for achieving their own personal goals, as well as the organizational goals. Motivation can be considered as a mechanism that can be used from public institutions' supervisors for creating and sustaining the desired workplace behavior or activities required for the achievement of both personal and organizational goals, as well as for the enhancement of public service performance. In Albania, there is a relatively insufficient research on the motivation of public institutions' employees. In order to study the factors that exert influence on the motivation of employees within the Albanian public sector, a research on the motivation of employees in the Municipality of Elbasan (MoE) has been undertaken. The main purpose of this research is to address how public employee performance in the MoE can be enhanced through the identification and analysis of the factors that impact the motivation of this institution's employees. Questionnaires were used for data collection for the study and the results obtained indicate the role that motivation plays on employees' performance in the $M o E$, while prioritized areas for immediate improvements were identified so to enhance job satisfaction, organizational commitment, and eventually organizational performance.
\end{abstract}

Keywords: Motivation, public sector employees, performance, Albania

\section{Introduction}

Motivation, as a complex phenomenon and a very important element of behavior, has attracted the attention of many academics and researchers for investigating it through a variety of settings such as, government, public institutions, organizations, and schools, to name few. In general, motivation has accumulated a large body of applied research studying it at the level of the individual, the group, and the organization. Many motivation definitions have been produced seeking to thoroughly describe this phenomenon. In an organizational context, motivation is considered as a mean or method used for getting employees to work and achieve the organizational objectives. As an internal psychological process that causes someone to act or behave in a purposive manner on a situation, motivation in the workplace context is central in enabling employees to achieve high level performance.

Dynamic development of societies requires changes in the public institutions. In Albania, there is a relatively insufficient research on the motivation of public institutions' employees. No relevant studies or quantitative research have been conducted so to highlight critical problems of employees motivation in the public sector. In order to study the factors that exert influence on the motivation of employees within the Albanian public sector, the research on the motivation of employees in the Municipality of Elbasan (MoE) has been undertaken. The main question that this research seeks to address is how public employee performance in the Municipality of Elbasan can be enhanced through the identification and analysis of the factors that impact the motivation of the employees. Specifically, the objectives of this research are: 1) to identify and assess the factors that motivate MoE's employees most; and 2) to provide recommendations for motivating employees in the MoE so to increase job satisfaction and organizational performance.

The paper unfolds as follows. First the theoretical background is presented. In the second part, the methodology of this research is described. Then, the empirical findings are presented, followed by the discussion of the generated motivation findings in the MoE. The conclusions of this research and motivation recommendations for enhancing employees performance in MoE constitute the final section. 


\section{Theoretical Background}

Employees, whether working in private organizations or public institutions, need to be motivated for achieving their own personal goals, as well as the organizational goals. With reference to workplace motivation, Rainey $(1997$, p.201) defines motivation as 'how much a person tries to work hard and work well - to the arousal, direction, and persistence of effort in work settings'. Further, Williams $(2004$, p. 6) explains motivation as a predisposition to behave in an intentional manner for achieving specific and unmet needs, and the inner force that drives individuals to achieve personal and organizational goals. A motivated employee believes that achieving specific goals requires specific behaviors and motivation is an effective tool for encouraging individuals to exert maximum efforts in successfully performing their task or job. Hence, the likelihood of increased efforts, performance, and organizational commitment is greater when employees are properly motivated for achieving their personal goals likewise the organizational goals. Based on the importance of motivation, we can certainly conclude that motivation is a mechanism that can be used for creating and sustaining the desired workplace behavior or activities required for the achievement of personal and organizational goals.

The dynamic relationship between people and their work has long attracted psychologists and other behavioral scientists. Researchers and practitioners have been studying motivation for more than a century and various theories have been offered to help interpret motivation and explain the factors that motivate people to behave in a specific way in the workplace. These theories provide the groundwork for individual workplace behavior and organizational development and can be applied to an array of organizational contexts aimed at motivating employees, but for the purposes of this research the main theory that will be utilized is Herzberg's Motivator-Hygiene Theory.

According to Motivator-Hygiene Theory, developed in 1959 by Herzberg, Mausner and Snyderman, motivation is composed of two largely un-related dimensions - hygiene factors and the motivators - the first ones are related to dissatisfaction, whilst the second to satisfaction (Herzberg et al., 1959). This theory notes that job satisfaction and job dissatisfaction are no opposites but separate dual continuums and the factors that lead to job satisfaction are different to those that lead to job dissatisfaction (Robbins \&Judge, 2009; Champoux, 2011). Meaning that the opposite of satisfaction is not dissatisfaction but no satisfaction, consequently the opposite of dissatisfaction is no dissatisfaction. The factors leading to satisfaction, labeled as motivators, are job content factors because they are related to the nature of the work itself and the rewards that are derived directly from the performance of that work (House \& Wigdor, 1967, p. 370). Hygiene factors, on the other hand are job context factors that lead to dissatisfaction, these factors are associated with the employee's relationship to the context or environment in which the work is performed (House \& Wigdor, 1967, p. 371).

Hygiene factors are necessary for the employee to experience in order to prevent dissatisfaction, but do not motivate them since they do not promote employees' self-development and growth. Hygiene factors are extrinsic jobrelated factors such as working conditions, salary, job security, organization policies, and quality of supervision. If these factors are missing or offered to an inefficient level cause dissatisfaction and consequently ineffectiveness within the organization (Herzberg et al., 1959). On the other hand, Herzberg's Two Factor Theory argues that only intrinsic job content factors, the motivators, motivate employees and lead to job satisfaction. Motivators are created by changing the nature of work while fostering ones needs for self-actualization and self-realization in the work. These factors include achievement, work itself, recognition, and growth, and thus employees are motivated when they are provided with the motivators that they find intrinsically rewarded and satisfied (Herzberg et al., 1959). Besides the dual factors of motivation, Herzberg's theory suggests a two-step process to motivate employees. Firstly, the elimination of dissatisfaction by providing the proper hygiene factors is necessary and following that is the creation of the conditions of job satisfaction by addressing the motivators associated with the work.

\section{Methodology}

This research study aimed to investigate public employees' motivation. Data on motivation were gathered from employees working in the Municipality of Elbasan. To guarantee that specific groups within this public institution are equally represented in the sample as well as to have a greater control on the composition of the sample, a simple random sampling was used and respondents were selected randomly. A questionnaire with close-ended questions was compiled for the data collection process. All participants received a 48 - item survey instrument designed to statistically investigate employees' motivation in the workplace. In addition to the job-related motivation variables relevant to this study, data were collected for demographic and other variables, the analysis for which is beyond the scope of this study. From the 50 questionnaires that initially were distributed, 38 questionnaires were returned for an overall response rate of 76 percent. 


\section{Results and Discussion}

\subsection{Demographic Data}

As shown in Table 1, out of 98 participants, $57.1 \%$ were males and $42.9 \%$ were females. The average age of the respondents ranged between $31-50$ years old. Almost half of the respondents had a master degree, while the remaining mostly possessed a bachelor degree. Specialists were dominant in the structure of respondents, making up approximately $50 \%$ of the total number of respondents, followed by supervisors (31.4\%) and administrators (17.1\%). Last, the average length of service in public institution ranged mostly from 2 to 10 years of service (higher distribution - $48 \%$ of the respondents - was observed in the time range from 2 to 6 years).

Table 1: Respondents' Demographic Data

\begin{tabular}{|c|c|c|c|c|c|}
\hline \multicolumn{6}{|c|}{ Demographic Data } \\
\hline \multirow{3}{*}{ Gender } & Male & $57.1 \%$ & \multirow{3}{*}{ Age } & $22-30$ & $17.1 \%$ \\
\hline & Female & $42.9 \%$ & & $31-39$ & $40.0 \%$ \\
\hline & Bachelor & $45.7 \%$ & & $40-50$ & $37.1 \%$ \\
\hline \multirow[t]{3}{*}{ Education } & Master & $51.4 \%$ & \multirow{5}{*}{ Working years in public institution } & $>50$ & $5.7 \%$ \\
\hline & Doctorate & $2.9 \%$ & & 0-1 year & $8.6 \%$ \\
\hline & Specialist & $51.4 \%$ & & $2-5$ years & $48.6 \%$ \\
\hline \multirow[t]{2}{*}{ Working Position } & Supervisor & $31.4 \%$ & & $6-10$ years & $37.1 \%$ \\
\hline & Administrator & $17.1 \%$ & & $>10$ years & $5.7 \%$ \\
\hline
\end{tabular}

\subsection{Job-Related Motivation Factors}

One of the main objectives of this research is to address the motivation matter by asking participant "What factors motivate you in your job?" The responses provided are applicable to the Herzberg's Two Factor Motivation Theory discussed in the previous section. Exploring the importance of these motivation factors is important to creating an environment that fosters. With the results, a public institution may gain valuable information that can be used by supervisors and managers to improve employee motivation and performance. Given that employee performance is an outcome of ability, work environment, and motivation (Griffin, 1990, p. 437), an understanding of what drives an employee to work enhances organizations performance.

The respondents were asked to assess motivation factors according to how much important each is in motivating them to do their best work. Table 2 presents the top six factors that respondents consider as the most important for motivating them. As can be noticed the top motivator selected is job security/stability, this reveals the top concern that employees constantly face due to the political employment phenomenon that is massively adopted in the Albanian public sector. This phenomenon and the general environment in Albania place public sector employees in a position of continuous uncertainty and insecurity for their job, therefore job security heads the list. Although job security is an extrinsic - hygiene factor according to Herzberg's typology, in the Albanian case it can be considered as an intrinsic motivator because it encircles more than just financial needs but also emotional wellbeing.

Table 2: Job-Related Motivation Factors

\begin{tabular}{ll}
\hline Most Important Job-Related Motivation Factors & \\
\hline Job Stability/Security & $94.3 \%$ \\
Recognition & $82.9 \%$ \\
Salary \& Benefits & $77.1 \%$ \\
Responsibility & $77.1 \%$ \\
Promotional opportunities & $74.3 \%$ \\
Achievement & $71.4 \%$ \\
\hline
\end{tabular}

The second most important item is recognition for the work done. Employees are motivated by feedback and recognition for the efforts they exert. Recognition requires attention from the supervisor or managers, because they usually think they 
know how to express recognition, but in reality managers seldom acknowledge and express appreciation for the work done by their employees (Wiley, 1997). Cherrington (1992, pp.52-53) recommends three principles when expressing recognition to subordinates: describe the desired behavior in specific terms, explain why this behavior is important; and express appreciation with some kind of incentive when the specific behavior is exhibited. Recognition is highly important for all employees in all levels. Recognition for work done has positive motivational effects leading to higher job satisfaction because employees will develop a positive self-concept in terms of esteem, actualization, growth and achievement (Levesque, 1987, p. 36; Lussier, 1997, p. 377).

Given the importance of recognition, respondents were asked to suggest what kind of incentives they would like to receive from their supervisor as a sign of recognition (Table 3). Overall job promotion leads the list; this implies that the primary motivating factor arises from the work itself. Job promotion provides a psychological effect on the employee; it concentrates on the intrinsic needs such as achievement, influence, and personal growth, and as such boosts selfesteem due to public recognition (Dawson and Dawson, 1990, p. 80). Financial incentives come second. Money is an extrinsic motivator, and therefore it does not come from the work itself. Monetary rewards are short-term motivators without having a long-lasting effect on employees' motivation. Recognition for the work done may be also manifested in other non-financial ways as well, such as professional development, increased responsibility, time off, or flexible work schedule. These non-financial motivators have longer lasting motivating effects and take into consideration the emotional needs of the employee.

Table 3: Recognition Incentives

\begin{tabular}{lc}
\hline Recognition Incentives Ranking & \\
\hline Job Promotion & $97.1 \%$ \\
Money & $94.3 \%$ \\
Professional Development & $51.4 \%$ \\
Increased Responsibility within current job & $54.3 \%$ \\
Time off & $40 \%$ \\
Flexible Work Schedule & $40 \%$ \\
\hline
\end{tabular}

Referring again to Table 2, the third ranked factors are Salary and Benefits, as well as Responsibility. The Albanian economic circumstances in combination with the standard of living reflect the importance of salary and other monetary benefits in public institutions' employees. Herzberg's two-factor theory classifies salary as a hygiene factor which does not cause job satisfaction, but if the amount of money the employee receives does not correspond to the time and quality of work done that may lead to job dissatisfaction (Armstrong, 2007, p. 66). Motivation is a psychological process which is highly affected by the employees' health and mental attitude, hence in order for them to be motivated and satisfied with their job they need to have certain basic needs fulfilled and money is the only mean to satisfy these needs. Therefore, money is an important motivational factor especially for operative employees and in some case for managerial employees as well (Chhabra, 2010, pp. 117-118).

Responsibility, promotional opportunities, and achievement are all forms of intrinsic motivation reflecting job enrichment and self-actualization, therefore if properly managed job satisfaction will be enhanced and eventually institutional performance. Motivation is an effective tool for creating inspiration and confidence, therefore by creating the proper conditions which may increase responsibility or provide greater possibilities for promotions or other achievements the "will to work", which is crucial for the achievement of organizational goal, is founded.

Responsibility, allows employees to take on some responsibilities and autonomy in their current job that normally assigned to supervision or management. In this manner the employees feel that their job is more interesting and provides them more recognition and opportunities for growth. In line with responsibility, come the promotional opportunities which in different settings generate increased motivation. In general, the goal of promotion is twofold, first to put an employee in the right job, and second to generate motivation (Gibbs, 1996, 2). The reason why promotion is considered as a very important motivator is because in many cases is considered as a form of pay per performance, but especially in public institutions where hierarchy is dominant promotion is also a source of reputation. It is the professional history of positions which provides the greatest evidence on growth and achievement. Last, achievement is strongly related to motivation and job satisfaction. Achievement is a sense of success on ones job and is directly linked to productivity and personal wellbeing. In a public institution setting, achievement is considered as a strong source of job performance because 
employees with high achievement motivation are result-oriented and possess strong instincts and determination of achieving both individual and organizational success (Epstein and Harackiewicz, 1992, 129).

\subsection{Subgroups Analysis}

So far we have looked the responses regarding the most important job-related motivation factors. But, it is important also to analyze the responses by subgroups, e.g. gender, age, education, working years, and position, to determine whether if there are variations in respect to these demographic variables. Not all demographic groups of employees place the same importance on each of the twelve factors. Individuals at different age, with different working years and position, may exhibit different motivational values.

\section{Gender}

When responses of men and women were analyzed, differences were found in their motivational preferences. A non-parametric test of significance revealed that females and males were different (at $p<0.01$ ) at job stability and security, responsibility, promotional opportunities (see Table 4). Women place greater importance on job stability and security and promotional opportunities. The males, on the other hand, place more emphasis on responsibility.

Age

Four age groups were analyzed (22-30; 31-39; 40-50; and over 50). Based on a one-way ANOVA analysis, that there exist no significant differences (at $p<0.05$ ) in the ranking of motivational factors in this subgroup besides selfdevelopment and growth factor where employees in the 31-39 age group place a greater emphasis (see Table 4).

Education

No significant differences were found in the motivational factors when responses were analyzed by education. A one-way ANOVA revealed that the only factors that differ in ranking among this subgroup (at $p<0.05$ ) are training opportunities and self-development and growth, for which employees with a doctorate degree have ranked as very important (see Table 4).

Working Years in Public Institution

When the responses were analyzed by the working years in public institutions through a one-way ANOVA, significant differences were found (at $p<0.05$ ) in quality of supervision, training opportunities, and self-development and growth (see Table 4). For those working for two or more years, quality of supervision is considered as an important motivational factor. With reference to training opportunities and self-development and growth, those who have been working in a public institution for a period of time from 5-10 years are considered as less important.

Position

When results are analyzes according to the working position, in general no significant differences were found. A one-way ANOVA revealed that resulting rankings of employees in different working positions were statistically different at the $p<0.05$ only for the salary and benefits motivational factor, those working in supervision positions place less importance on salary and benefits in comparison to specialists and administrators.

Table 4: Summary Information of preferences for each job-related motivational factor

\begin{tabular}{|c|c|c|c|c|c|}
\hline \multicolumn{6}{|c|}{ Subgroups reporting higher positive significance for a factor's importance } \\
\hline Factors & Gender & Age & Education & Working years & Position \\
\hline Salary \& Benefits & & & & & Specialists \& Administrators \\
\hline Quality of Supervision & & & & $>2$ years & \\
\hline Job Stability/Security & Women & & & & \\
\hline Responsibility & Men & & & & \\
\hline Training opportunities & & & Doctorate & $0-5$ years $\&>10$ years & \\
\hline Promotional opportunities & Women & & & & \\
\hline Self-Development and Growth & & -39 years & Doctorate & $0-5$ years $\&>10$ years & \\
\hline
\end{tabular}

\section{Recommendations for Public Institution Management}

The striking result of this research is the clear indication of job security, recognition, and money as motivators. Currently, the Albanian economic and political circumstances jeopardize the future employment and the standard of living of the Albanian public institutions' employees. Because employees overall expressed the importance of job security as a motivator the Albanian Civil Official Law is critical. Although this law is in force, a wide understanding and implementation 
of it is missing. Therefore, employees need to be well-informed in terms of the rights and restrictions arising from this law. Clearly employees need reassurance about job security, but they also place high importance on recognition. Recognition is imperative in enhancing employees' self-esteem and confidence by recognizing their contributions. Giving feedback and recognition has a positive psychological effect on employees. Recognition for work done may be manifested through promotional and development opportunities and money; filling positions from inside the institution can be an effective recognition tool. Money, in its clear form, on the other hand is difficult to be implemented in a public institution due to the strict regulations on payments, but promotions in most of the cases are considered by the employees as an indirect form of increased salary. Additionally, recognition can be supported by increase responsibility and autonomy in ones job, through flexible scheduling or time off providing in that manner freedom to pursue training or educational degrees.

Public institutions employees' motivation becomes more complicated when salary and benefits enter the equation. Scholars argue that public employees have an intrinsic motivation to serve the public good. Nonetheless, in Albania the intrinsic motivation, as well as the general public service morale is stranded in low levels. Public sector employees continuously demand higher wages but government budget cannot satisfy this consistent demand. Due to the Albanian governmental and economic constraints, the Albanian public institutions need to place greater emphasis on intrinsic motivation rather than to the extrinsic one such as salary. Therefore, tactics for applying public service motivation selecting candidates with public service values, designing meaningful jobs, creating conducive work environments, and encouraging leaders with values and promoting civic-minded societies (Paarlberg et al., 2008) - are a prerequisite for enhancing public sector employees' motivation.

\section{Conclusions}

Employees, whether working in private organizations or public institutions, need to be motivated for achieving their own personal goals, as well as the organizational goals. Motivation, as an internal psychological process that causes someone to act or behave in a purposive manner on a situation, in the workplace context is central in enabling employees to achieve high level performance. In the Albanian public sector exists an inability to effectively motivate employees so to increase job satisfaction and performance, therefore the purpose of this research was to study the factors that exert influence on the motivation of employees within the Albanian public sector, specifically in the Municipality of Elbasan $(\mathrm{MoE})$. The objectives of this research were: 1 ) to identify and assess the factors that motivate MoE's employees most; and 2) to provide recommendations for motivating employees in the MoE so to increase job satisfaction and organizational performance.

The participants of this research ranked as the top six factors that motivate them in their jobs:

1. Job Security

2. Recognition

3. Salary and Benefits

4. Responsibility

5. Promotional Opportunities

6. Achievement

The findings of this research also suggest that regardless of gender, age, education, working position and working years, employees in the MoE seem to be of one accord regarding recognition as a motivational factor. In terms of job security female employees seem to place higher emphasis, whereas male employees emphasize responsibility. With reference to the working position salary and benefits are more important for specialists and administrators. Furthermore, those who hold a doctorate degree and have been working in the public sector for 2 to 5 years or more than 10 years ranked training and promotional opportunities as a very important motivational factor. Last, self-development and growth are ranked as important factors from those employees who are 31-39 years old, have a doctorate degree, and have been working in the public sector for 2 to 5 years or more than 10 years.

These factors reflect the currents state of employee needs in the Municipality of Elbasan and imply that a recognition incentive system and public service motivation strategies and tactics may be used for motivating employees in order to create and sustain the desired workplace behavior required for the achievement of higher individual and institutional performance. 


\section{References}

Armstrong, M. \& Murlis, H. (2007.) Rewards Management: A Handbook of Remuneration Strategy and Practice. Kogan Pages Limited: London.

Champoux, J. (2011). Organizational Behavior: Integrating Individuals, Groups, and Organizations (4th Ed.). New York: Routlegde.

Cherrington, D.J. (1992). "Follow-through on award programmes", HR Magazine, 37(4), 2-55.

Chhabra T.N. (2010). Fundemantals of Management, (4th Ed.) by K V Sharma-978-81-906332-6-0.

Dawson, K.M. \& Dawson, S.N. (1991). "The cure for employee malaise - motivation", Clinical Laboratory Management Review, 5(4), 296-302.

Gitman, L. J. \& McDaniel. C. (2009). The Future of Business: The Essentials. Mason: South - Western Cengage Learning.

Griffin, R.W. (1990). Management (3rd Ed.). Houghton Mifflin Company: Dallas.

Ilgen, D. R. \& Klein, H. J. (1988). "Individual Motivation and Performance: Cognitive Influences on Effort and Choice" in R J Campbell and Associates (Ed.), Productivity in Organizations, London: Jossey-Bass.

Hezberg, F., Mausnek, B., \& Snyderman, B. (1959). The Motivation to Work (2nd Ed.). New York: John Wiley and Sons.

House, J.H. \& Wigdor, A.L. (1967). "Herzberg's Dual Factor Theory of Job Satisfaction and Motivation: A Review of the Evidence and a Criticism", Personnel Psychology, 20 (4), 369-390.

Latham, G. P. (2007). Work motivation: history, theory, research, and practice. California: Sage Publication, Inc.

Levesque, P. (1987). "Employee motivation: a little recognition goes a long way", Industrial Management, 11(1), 35-7.

Lussier, R.N. (1997). Management, South-Western College Publishing: Cincinnati, OH.

Nohria, N., Groysberg, B. \& Lee, L. (2008). "Employee Motivation: A Powerful New Model" Harvard Business Review, 86(7/8), 78-84.

Paarlberg, L.E., Perry, J.L. \& Hondeghem, A. (2008). "From Theory to Practice: Strategies for Applying Public Service Motivation," in J. L. Perry and A. Hondeghem (Ed.), Motivation in Public Management: The Call of Public Service. Oxford University Press: New York

Pride, W. M., Hughes, R. J. \& Kappor, J. R. (2010). Business (10 th Ed.). Mason, Oh: South - Western Cengage Learning.

Rainey, H G. (1997). Understanding and managing public organizations. (2nd Ed.). San Francisco, CA: Jossey-Bass Publishers.

Robbins, S.P. \& Judge, T.A. (2009). Organizational Behavior (13 ${ }^{\text {th }}$ Ed.). San Diego State University: Prentice-Hall Inc.

Wiley, C. (1997). "What motivates employees according to over 40 years of motivation surveys", International Journal of Manpower, $18(3), 263-280$.

Williams, J. R. (2004). "Job Satisfaction and Organizational Commitment", Sloan Work and Family Encyclopedia, Retrieved June 07, 2015, from: http://www.bc.edu/bc_org/avp/wfnetwork/rtt/wfpedia/index.html

Gibbs, M. (1996). "Promotion and Incentives", Unpublished working paper, University of Chicago.

Epstein, J.A. \& Harackiewicz, J.M. (1992). "Winning is not enough: The effects of competition and achievement orientation on intrinsic interest", Personality and Social Psychology Bulletin, Vol.18, pp. 128-138. 